\title{
Everyone has something worthwhile to say: an introduction to Salford Zine Library
}

Steve Carlton (1) 0000-0002-2851-7402 and Ingrid Francis (1) 0000-0002-1615$\underline{4181}$

https://doi.org/10.1017/alj.2018.9

Published online: 27 March 2018

Correspondence to Steve Carlton (stephen.b.carlton@gmail.com)

Salford Zine Library is a volunteer-run, not-for-profit collection of approximately 2,000 zines and other self-published materials housed at Nexus Art Café in Manchester. The makeup of the collection, the way it has been built and its comparatively less restrictive access arrangements make it a unique resource in the UK. Over the last seven years the zine library has grown from a small personal collection to a resource that attracts zine enthusiasts from around the UK and beyond.

\section{A brief history}

Salford Zine Library was originally set up by Manchester-based illustrator Craig John-Barr in 2010, and was housed in Islington Mill, an artists' studios in Salford. At this point the collection was primarily made up of zines that Craig had accumulated over the years, but was later supplemented with donations received in response to calls on his blog and on social media.

In 2011 the collection was exhibited at Salford Museum and Art Gallery, alongside Craig's short film Self-publishers of the world take over ${ }^{1}$, which featured zine makers talking passionately about zines and zine making. Once the exhibition had finished in early 2012, the library needed a new home. At this point Nexus Art Café offered the permanent use of a disused space and crowdfunding was sought to raise funds to decorate and furnish the room with shelving and other storage. The collection has been there ever since.

In 2013, Craig moved to the United States and handed over the running of the zine library to Stephen Carlton, a librarian, and Elizabeth Murray Jones, a textile artist. After successfully collaborating on Northwest Zinefest in 2015,

\footnotetext{
1 "Self-publishers of the world take over!" Youtube, accessed January 19, 2018, https://www.youtube.com/watch?v=9Qfev2293lc
} 
they were joined by Ingrid Francis, a freelance curator and librarian, and writer Cherry Styles. Together they sought to build upon the zine library's previous successes and help it become an even better community resource to promote the enjoyment of zines.

Since 2013, the library has successfully been awarded Heritage Lottery Fund and Arts Council England funding to support some of its activities, including: creating a new website ${ }^{2}$, cataloguing some of the collection, hosting a series of workshops and exhibitions, and organising two zine fests in 2015 and 2016. These funding streams are not continuous, though, so much of the time the zine library operates without any funding and relies on volunteers.

\section{Visiting the zine library}

Salford Zine Library is contained in a room at Nexus Art Café in Manchester. The room is open to the public during café opening hours and is not staffed. Visitors are able to browse the shelves and read zines from the collection either in the zine library itself, where seating is available, or in the main café space. Café staff keep an eye on the library but ultimately visitors are trusted to respect the space and ensure they leave it tidy.

The zine library team visit periodically to tidy up the shelves and collect any donations that might have been left. Where group visits have been arranged in advance, one of the team will make sure they're able to attend to supervise and offer an introduction to the collection. The library has hosted visits from various groups of students at secondary school, FE and HE levels from a range of subjects, and these sessions always receive excellent feedback.

As the library isn't staffed and there is no kind of visitor counter in the room, it's impossible to know exactly how many people actually visit the library. Anecdotal evidence from the café staff, as well as comments on social media, suggest that the library is well used. Visitors are not all local either - zine enthusiasts from around the UK and beyond often make a pilgrimage to the library when they are in the area.

Many zine collections are kept as part of university special collections departments, or as part of museum and gallery collections. ${ }^{3}$ Often visitors need

\footnotetext{
${ }^{2}$ Salford Zine Library, accessed January 19, 2018, https://salfordzinelibrary.co.uk/

3 "UK and Ireland Zine Librarians directory", UK and Ireland Zine Librarians, access January 19, 2018 https://uizl.wordpress.com/uk-and-ireland-zine-libraries-directory/
} 
to book appointments to gain access to these areas. While there are justifiable preservation related reasons for this, it does little to encourage browsing collections for leisure. ${ }^{4}$ The focus is often on using zine collections for research purposes, understandably, as providing support to researchers is a primary aim of these organisations. It can also be more difficult to gain access to these collections if you are not in some way affiliated with the organisation.

Salford Zine Library, and other non-institutional collections, offer a nonintimidating space for people to browse their collections without having to justify their interest. The library is housed in a relatively small room, but there is comfortable seating available to encourage people to make themselves at home and enjoy reading the zines. Feedback received via email and on social media suggests that some visitors spend several hours in the library, browsing the collection and discovering new zines to read.

\section{Aims of the zine library}

According to the zine library's website it 'seeks to preserve and provide access to zines from around the world, as well as promoting zines and DIY culture through workshops, exhibitions and other events' [3]. The first part of that statement around preserving and providing access to the collection could be talking about any library in the world.

The second part around promoting zines and DIY culture is slightly different to the modus operandi of a typical library, it could be argued. The library wants to actively encourage not just the enjoyment of the collection, but involvement in zine making and DIY culture. Salford Zine Library team member Cherry Styles produced the 16-page guide What are zines anyway? which was distributed at events and at the library itself to help people get started with making their own zines. ${ }^{5}$ As well as providing encouragement, the collection itself serves to inspire people to 'do it themselves', because the library believes that everyone has something worthwhile to say.

\footnotetext{
${ }^{4}$ Siobhán Britton, "What we do is secret? A study of issues relating to the collection, care, and accessibility of zines in institutional and alternative collections in the UK" (MA diss., University College London, 2013), 22-23.

${ }^{5}$ Cherry Styles, "What are zines anyway? How + why to get involved NOW", accessed January 18, 2018, https://issuu.com/cherrystyles/docs/zinefest16
} 


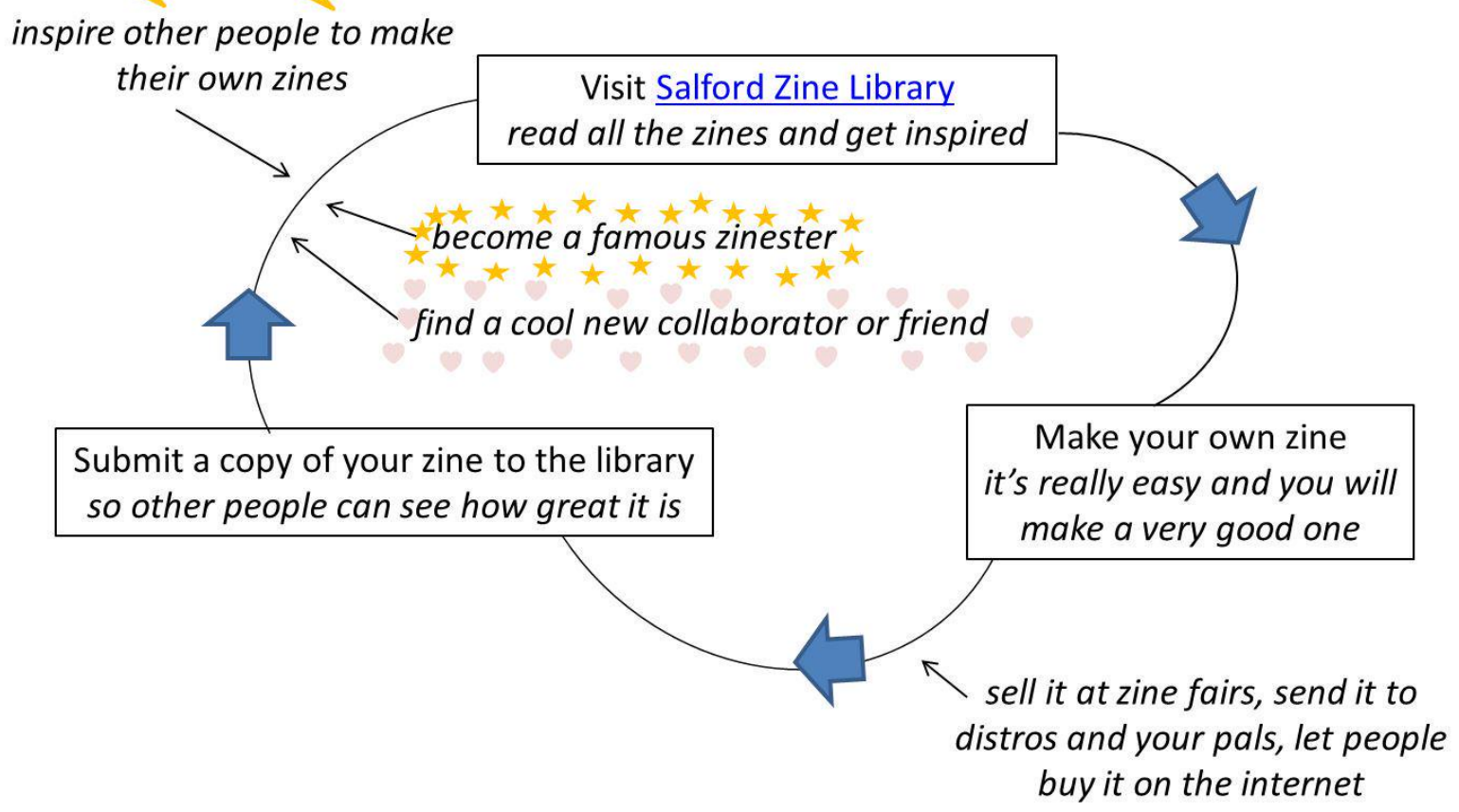

A light-hearted diagram titled 'Salford Zine Library Zinesters Cycle', tweeted by the library in 2015, attempts to explain how the library aims to encourage visitors to make their own zines. ${ }^{6}$

\section{Collection development}

'Everyone has something worthwhile to say' would be a reasonable summary of Salford Zine Library's collection development policy, in that it doesn't really have one. All of the zines in the collection were donated: either through the post or in person at events. People can also donate zines at the library itself by leaving them in a donations box. Donations come in all shapes and sizes from all over the world. Often the library is asked to take larger donations from people clearing out space in their houses or downsizing their personal collections.

The library doesn't attempt to curate the collection, so everything that is donated goes on to the shelves, regardless of content. This relaxed attitude to collection development might be tested if the library was to receive any zines that were in any way discriminatory, but that hasn't happened yet.

\footnotetext{
${ }^{6}$ Salford Zine Library (@SalfordZineLib), “I knocked up a "Salford Zine Library Zinesters Cycle" in my lunch break. Very inspiring stuff." Twitter, June 5, 2013, https://twitter.com/SalfordZineLib/status/606799534421864449
} 
In recent years, there have been debates within the zine community about what a zine is and what a zine isn't. ${ }^{7}$ The Salford Zine Library team all have personal opinions on this issue, but that doesn't have any effect on what goes on the shelves at the library. The team may think a submission is actually more of an artist's book, but if someone has chosen to send their work and identifies their work as a zine then it's made available in the library.

\section{Cataloguing the collection}

As part of their successful 2014 Heritage Lottery Fund grant application, the library was given funds to design and build a new website with basic cataloguing functionality. Until this point the library team weren't even sure how many zines were in the collection, let alone what all the zines were. Various options for creating a catalogue for the collection were investigated, but in the end a decision was made to use Wordpress rather than a purposebuilt library management tool. The library's needs were best met by a simple, sustainable solution that could be used by non-specialists rather than a complex system that would need ongoing support.

Each zine in the library catalogue has the following metadata fields: title, author(s), year of publication, size, subject, keywords, and an image of the front cover. The very nature of zines makes them particularly difficult to catalogue, so some of these fields are often left blank as the information isn't available. Each zine also has a 'description' field, almost like a MARC21 520. Here the zine library team member cataloguing provides a summary of the zine, along with links to the zine makers' website/shop where they can be found. Unlike a standard library catalogue, these descriptions are very informal and are intended to encourage website visitors to find out more about the zines in the collection.

Each issue of Poor Lass includes contributions around a theme relating to class and feminism. Every single issue is brilliant and this one, the sixth issue, contains lots of excellent pieces around health. With a cover by the preternaturally (I just learnt this word FYI) talented Polly Richards, there's even more reason to grab yourself a copy/pop in to the library and have a read. ${ }^{8}$

\footnotetext{
7 "The economy of zines", Cool Schmool Zines, accessed January 18, 2018, http://www.coolschmool.com/2017/03/the-economy-of-zines.html

8 "Poor Lass 6: Health", Salford Zine Library, accessed January 19, 2018, https://salfordzinelibrary.co.uk/library/poor-lass-6/
} 
At the end of displayed metadata the following message is added by default: 'If you would like your zine to be removed from this website, please email salfordzinelibrary@gmail.com.' As many of the zines the library receives are from third parties (i.e. people who aren't the original creator) the library recognizes that some zine makers may be uncomfortable with their work being on the website and is happy to remove any content on request.

The catalogue helps visitors get a feel for the zines that are in the collection, but it is not exhaustive. About $30 \%$ of the collection has been catalogued so far, but there are plans to work through much of the backlog in 2018.

Furthermore, the subjects assigned to zines in the catalogue would, typically, be reflected in the way that the collection is shelved. Unfortunately, this isn't possible. The nature of the zine library - i.e. very rarely staffed - makes it difficult to retain any kind of shelving system. The library experimented with shelving the collection into subjects in 2013 but the zines quickly got mixed up and the subject sections became unhelpful as a result.

While shelving zines into discrete subjects isn't possible, this does open up opportunities for serendipitous discovery. The collection is shelved in almost no order whatsoever - larger zines are shelved together but everything else has been shelved with little thought as to where it belongs. Therefore, when visitors are looking for zines to read, they're likely to come across all kinds of zines that they perhaps might not have thought about reading. For some this will be a source of frustration, for others it will broaden their horizons and give them something new to enjoy.

\section{Northwest Zinefest and other outreach activities}

In 2014, Ingrid Francis approached Salford Zine Library and local writer Cherry Styles to pitch the idea of collaborating on a zinefest for Manchester. The outcome of this meeting was Northwest Zinefest. ${ }^{9}$ An event endorsed by Salford Zine Library and involving its team, the zinefest was named 'Northwest' because of the political geography of Salford and Manchester. The name 'Northwest Zinefest' also has a good ring to it.

Organising a zinefest provided a number of opportunities for the zine library to reach a wider audience. The zinefest helped to raise awareness of the zine library, among zine makers, zine enthusiasts and visitors to the event. In the months after the first Northwest Zinefest, donations to the library increased

\footnotetext{
${ }^{9}$ Northwest Zinefest, accessed January 19, 2018 https://northwestzinefest.wordpress.com/
} 
significantly. Coverage of the event in the media also helped to set up links with a number of cultural institutions that the library still works with today.

While the team are aware that the Northwest of the UK encompasses more than Greater Manchester, at present the zinefest has not taken place outside of this area. The team are open to the idea of hosting future events outside of Greater Manchester if a suitable venue can be found and resources are available.

After the success of the first zinefest in 2015 , Ingrid and Cherry were invited to become an official part of the team at Salford Zine Library. Ingrid leads on and continues to maintain the social media accounts and online presence for Northwest Zinefest, focusing on the outreach and events that are delivered by the team.

The zine library aims to deliver as many outreach events as possible around the team's full time work responsibilities. These often take the form of zine making workshops that provide a space for zine makers to get together and inspire each other. The library also regularly hosts exhibitions: either showcasing the work of individual zine makers or focusing on a theme, like perzines.

In 2017 the team took a year off from organising the zinefest. This was, in part, due to other commitments but also the zine library had delivered over 20 outreach workshop events in 2016 and 2017 as part of their successful Two Thousand and Six Zine Arts Council England funded project. Logistically it was not felt that the team had the capacity to fund and organise a zinefest that year. At the time of writing, the team are in the planning stages of organising Northwest Zinefest 2018.

\section{What's next?}

The library will be moving to a new purpose-built space in Nexus Art Café so will be closed until April 2018. ${ }^{10}$ It's hoped that this time can be used to catalogue some of the backlog of zines that haven't yet been added to the website. The new zine library will also be much easier to access: rather than having to walk through the café, the zine library will soon be the first thing that they see on entering the building. This will hopefully re-assure visitors that

\footnotetext{
10 "Zine Library Temporary Closure and Move", Salford Zine Library, accessed January 19, 2018 https://salfordzinelibrary.co.uk/news/zine-library-temporary-closure-and-move/
} 
they don't need to purchase anything to enjoy the collection and encourage more people to visit the library.

As mentioned, there plans for a Northwest Zinefest in 2018. The library is looking for funding to help make this possible. The library's other activities for the year are also dependent on funding being available. Whether the library has funding or not, it will still aim to organise the zinefest and other outreach events and continue to promote zines and zine making wherever and however it can. 